\title{
The Effect of Runoff on Saltwater Intrusion in Weak Tide Estuary
}

\author{
Gao shiyou, Chen Rongli, Lu chen \\ (Pearl River Hydraulic Research Institute, Guangzhou, China, 510611)
}

\begin{abstract}
Modaomen Estuary is a typical weak tidal estuary. The saltwater movement distance is not monotonic relationship with the tidal dynamics, it is also related to the strength of the salt wedge. In different phase of saltwater intrusion, saltwater intrusion distance has different responses to runoff. Through physical model tests, salt inhibition effect due to runoff at different stages had been studied. With the same total runoff in the half moon tidal cycle, methods of adjusting the amount of runoff distribution for better salt inhibition effect are proposed in the article. Increasing the runoff after neap tide can effectively inhibit the intrusion of saltwater.
\end{abstract}

\section{Introduction}

Modaomen Estuary is one of the main estuaries of the Pearl River. It is the source of water supply for Zhuhai, Macao, Zhongshan and other cities. In recent years, with the rapid development of social economy and population, the demand for fresh water has been increasing. The problem of water supply blocked by salt water intrusion has become serious. The water conservancy department restrains the salt water intrusion by dispatching the upstream reservoir to enlarge the runoff, thus increasing the water-intaking opportunity in the estuary area. The saltwater intrusion process varies periodically with the semilunar tide. As shown in Fig.1, increasing the runoff at different stages of the saltwater intrusion will result in different effects of saltwater suppression. When to increase the runoff is more effective in restraining salt water intrusion and getting more water-intaking time is a quite realistic and complex problem, which is put forward in this paper.

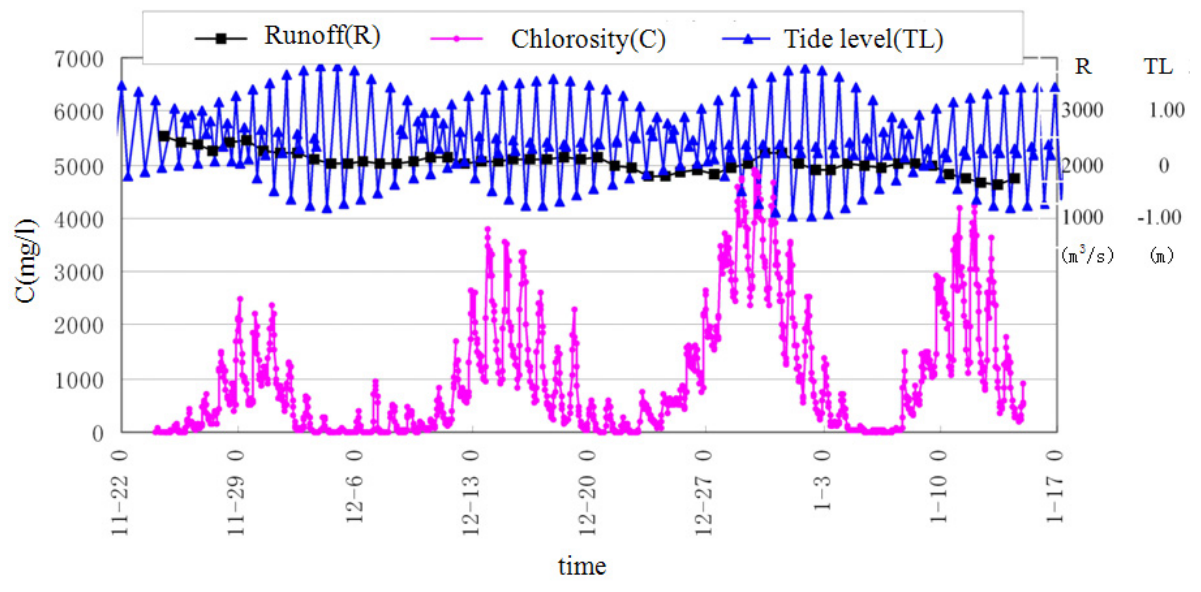

Fig.1 Chart of chlorosity, tide level and runoff in Ping Gang pumping station in 2005-2006 


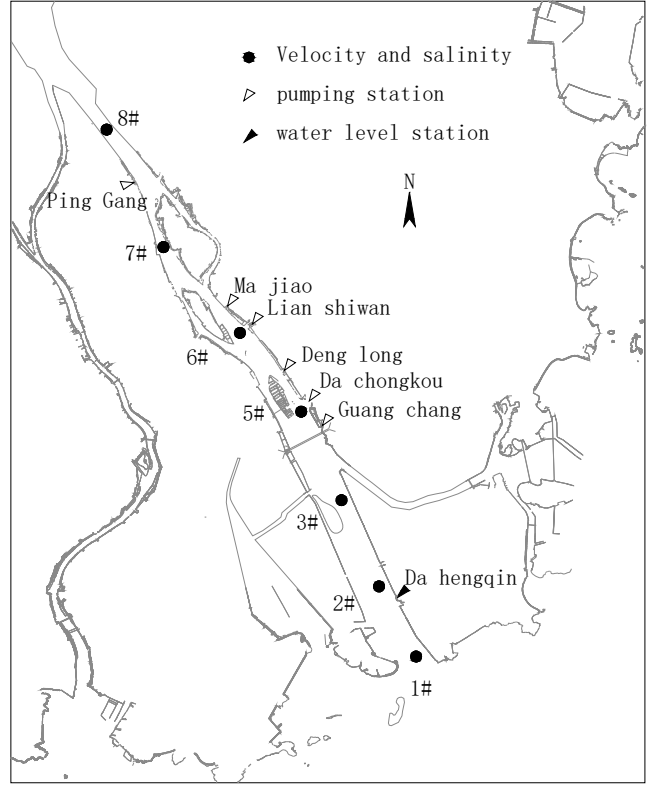

Fig.2 Layout of saltwater intrusion model in Modaomen

\section{Mechanism of saltwater intrusion in the Modaomen Estuary}

Fig. 1 shows the relationship between salinity process and tide level process at Pinggang pumping station upstream of Modaomen (see Fig. 2). As can be seen from the chart, the upstream salinity began to rise before neap tide, peaked a few days before spring tide, then dropped to neap tide and rose again and again. The variation of saltwater intrusion distance in Fig. 3 is also consistent with this, that is, the intrusion began before neap tide and ended before spring tide. The salty boundary refers to the position of the surface salinity $0.5 \mathrm{psu}$. From the surface and bottom salinity processes at several stations in Fig.4, the surface salinity is consistent with the above law, while the bottom salinity changes in the opposite way. The salinity is high at neap tide and low at spring tide.

Because the Modaomen estuary is a weak tide estuary, the main driving force of saltwater intrusion is density flow, which invades in the form of saltwater wedge. Therefore, the increase of tidal power will reduce the effect of density flow by strengthening the mixing, thus reducing the distance of saltwater intrusion. Through a large number of prototype observations, the development process of salt water intrusion in Modaomen is revealed: the tidal dynamics is weakest during the neap tide period, and the stratification of salt and fresh water is most obvious; after the neap tide, with the increase of tidal dynamics and the increase of mixing, the salt in the bottom layer gradually diffuses to the surface layer, and at this stage the surface salinity increases while the bottom salinity decreases. The surface salinity reached the maximum on the two or three days before the spring tide (see AB section in Fig.4). During the spring tide, both the surface and bottom salinity decrease day by day. Although the bottom salinity is quite high at high-water slack, the salinity decreases day by day at low-water slack (see BC section in Fig. 4).After the middle tide during the spring tide to the neap tide, the stratification of salt and fresh water gradually became obvious with the decrease of tidal power. Salt water invades upstream from the bottom of the river in the form of a salt wedge. The salinity at the bottom increased daily, while the surface salinity did not increase (see CD section in Fig.4). Runoff mainly flows through the surface layer.

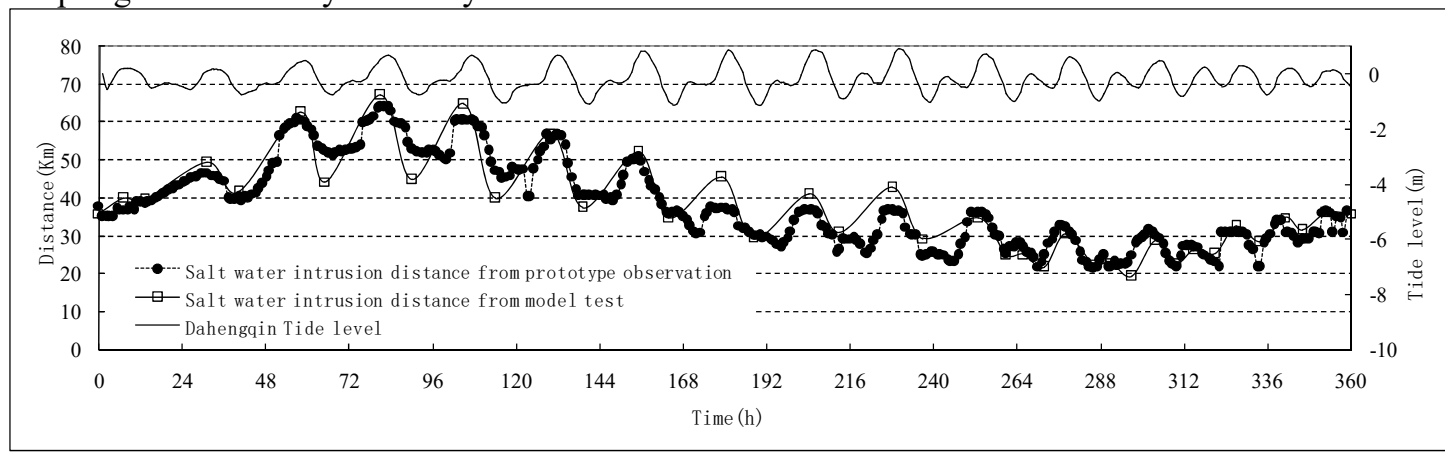

Fig.3 Variation of saltwater intrusion distance

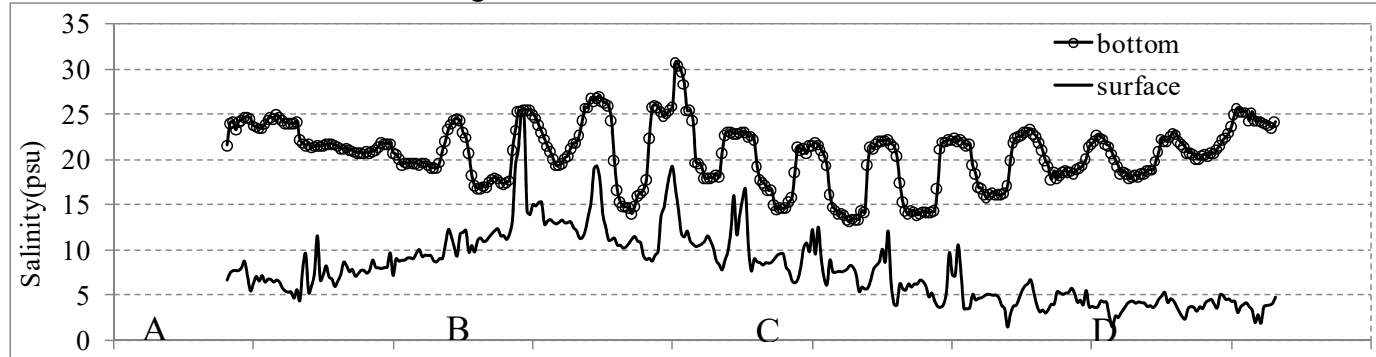

2009-12-9 2009-12-11 2009-12-13 2009-12-15 2009-12-17 2009-12-19 2009-12-21 2009-12-23 2009-12-25 2009-12-27 


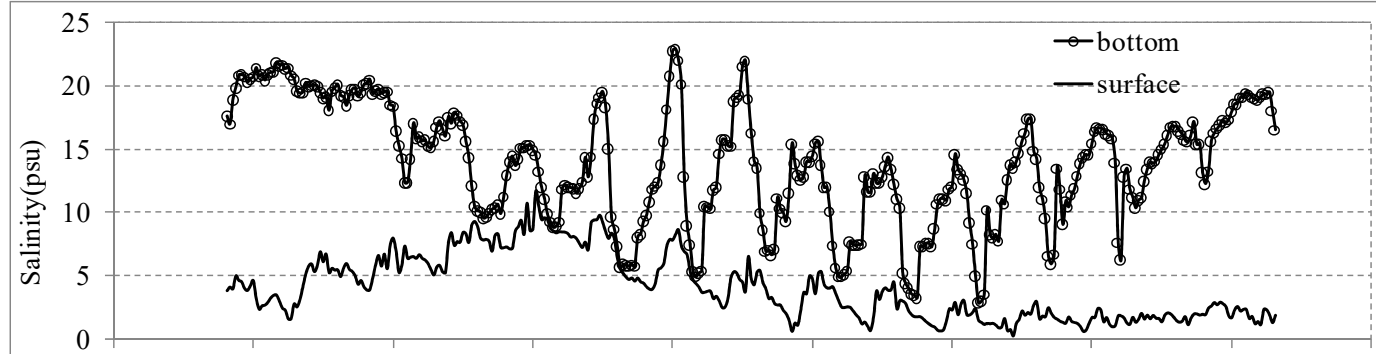

2009-12-9 2009-12-11 2009-12-13 2009-12-15 2009-12-17 2009-12-19 2009-12-21 2009-12-23 2009-12-25 2009-12-27

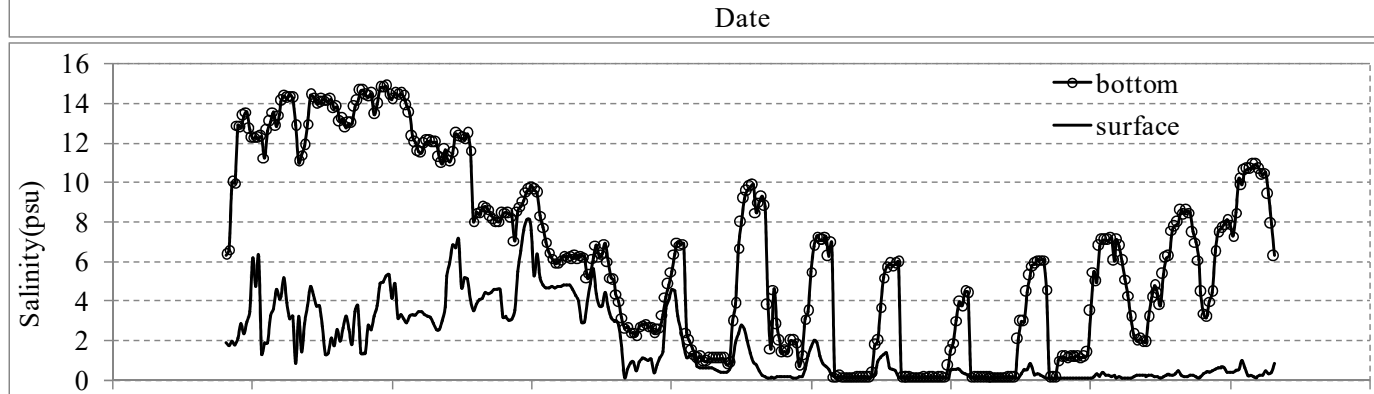

2009-12-9 2009-12-11 2009-12-13 2009-12-15 2009-12-17 2009-12-19 2009-12-21 2009-12-23 2009-12-25 2009-12-27 Date

Fig.4 Variation of Modaomen waterway salinity In December 2009

\section{Model overview}

In order to fully understand the law of saltwater intrusion and its response to upstream runoff in Modaomen Estuary, a physical model test of saltwater intrusion in Modaomen Estuary was carried out. The scope of the model is shown in Fig.2. The upper reaches of the tidal zone are modeled by twisted watercourses. The model is designed according to gravity similarity criterion and buoyancy similarity criterion. The horizontal scale is $\lambda l$ $=1000$, vertical ratio $\lambda h=66.7$, salinity ratio. $\lambda s=1$. The model validates the tidal level process, the stratified velocity process, the stratified salinity process and the variation process of the salt water intrusion distance, and obtains ideal similar results, shown in Fig.3.

\section{Test results}

(1)Single day tide test results

In order to study the effect of tides and runoff on saltwater intrusion, a single day tide test was conducted. It is to use the same day's tide type, including spring tide, middle tide, neap tide, to run continuously until the hydraulic parameters and salinity distribution reach a stable state, and then get the stable saltwater intrusion condition under the tide type and runoff conditions, and measure the saltwater intrusion distance at high-water slack and low-water slack. The maximum saltwater intrusion distance corresponding to different tide ranges and runoff is shown in Fig.5.

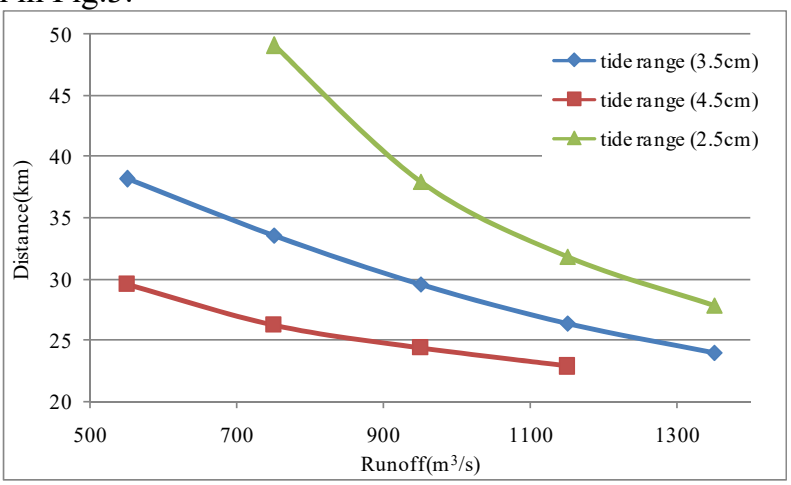

Fig.5 Saltwater intrusion distance

The following conclusions can be drawn from the chart: firstly, the smaller the tidal range, the farther the salt water intrusion; secondly, the greater the runoff, the smaller the distance of the salt water intrusion; thirdly, the farther the salt water intrusion distance from the estuary, the more sensitive the effect of the runoff on it; finally, when the tidal current and runoff are very small, the salt water will intrude rapidly.

These understandings are different from those obtained from measured data, which shows the spring tide with high salinity and long saltwater intrusion distance, and the neap tide with low salinity and short saltwater intrusion distance. In natural conditions, there is no repetitive effect of a tide type due to the continuous variation of tides with different tidal ranges, and saltwater intrusion takes several days to accumulate. In reality, It is during the neap tide period when salt water is concentrated at the bottom of the river and the surface 
salinity is not high. Because water works usually use surface salinity to determine whether to take water, the intrusion distance and salinity during the neap tide period are not high.

After the neap tide, the bottom salt water intrudes farthest. With the increase of tidal mixing power, the bottom salt water diffuses to the surface layer, making the surface salinity reach the highest before the spring tide, and the surface salt water intrude farthest.

Therefore, the above test phenomena can only be expressed by some regularity. But it can be explained that tidal power plays a role in restraining the saltwater intrusion in the weak tide estuary.

(2) semilunar tide test results

Model experiments were conducted to observe the intrusion of saltwater under different constant runoff conditions. The experiment was controlled by the semi-monthly tide level measured at the Modaomen in December 2009. The archetypal semilunar tide type lasted 360 hours as shown in Fig. 6. The initial stage was neap tide, the middle stage was spring tide, and finally returned to neap tide. The highest tide level was $1.08 \mathrm{~m}$, the lowest tide level was $-1.22 \mathrm{~m}$, the maximum tidal range was $2.30 \mathrm{~m}$, and the average tide level was $-0.07 \mathrm{~m}$.
These characteristics are equivalent to the average annual value of the dry season. The upstream constant runoff is controlled at $550 \mathrm{~m}^{3} / \mathrm{s}, \quad 750 \mathrm{~m}^{3} / \mathrm{s}$ and $950 \mathrm{~m}^{3} / \mathrm{s}$ respectively.

The observed distance of the saltwater intrusion is shown in Fig.6. It can be seen from the diagram that although the influence of different runoff on the intrusion distance is different in the tidal period, the difference is not too great, that is, when the salt water intrusion is in the form of a saltwater wedge, the influence of the runoff on the surface salinity is not too great. When the bottom salty diffuses to the surface during the middle tide, the runoff is sensitive to the intrusion distance. Because the runoff is inversely proportional to the tidal current, when the runoff is small, the tidal current will be large, and will push the mixed salt water upstream, so that the intrusion distance will rise sharply; when the runoff is large, the diffused salt water will be carried downstream faster by the runoff. It can be seen that the magnitude of the runoff is most sensitive to the intrusion distance in the middle tide period after the neap tide, that is, to increase the runoff in this period to accelerate the release of mixed saltwater, can more effectively inhibit the salt water intrusion.

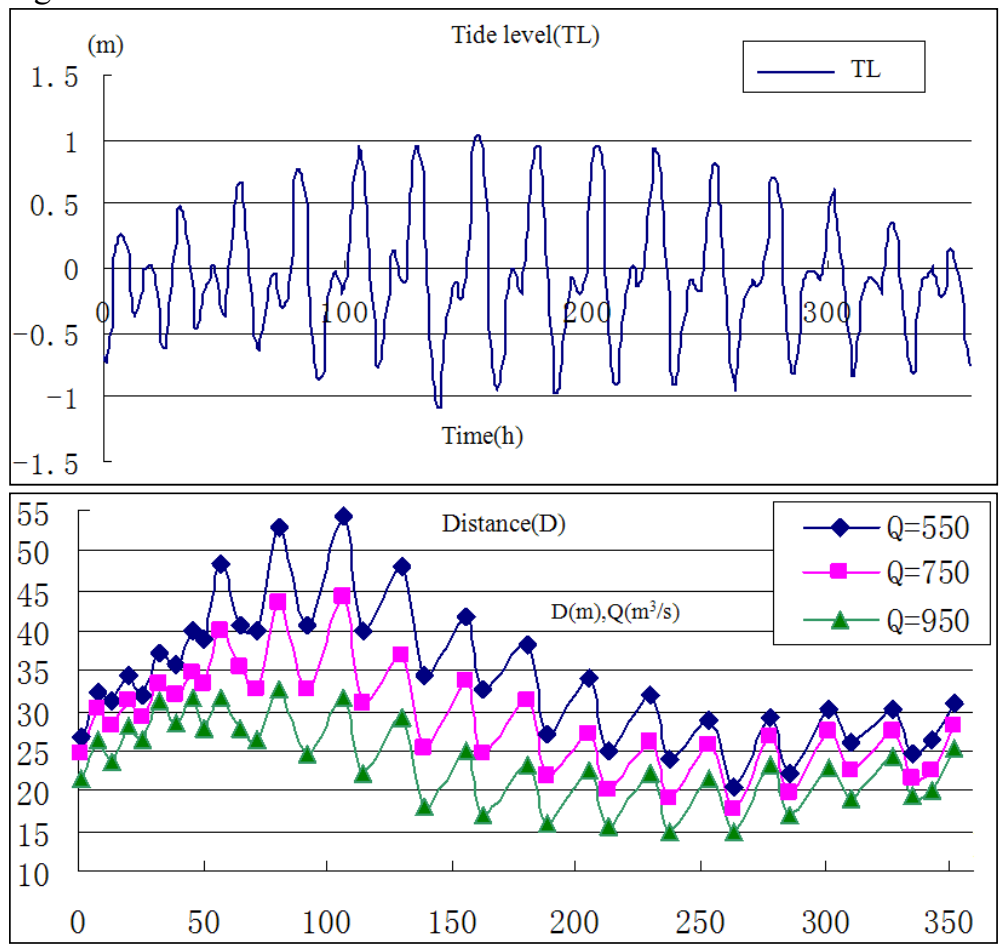

Fig.6 distance change by different runoff during semilunar tide

In order to verify this effect, the average runoff of the semimonthly tide ( 15 days) is $750 \mathrm{~m}^{3} / \mathrm{s}$, and the upstream runoff is increased to $900 \mathrm{~m}^{3} / \mathrm{s}$ in the mid-tide period after the neap tide, totaling 90 hours, and $700 \mathrm{~m}^{3} / \mathrm{s}$ in the other 270 hours.

The variation process of the measured intrusion distance is shown in Fig.7. It can be seen from the chart that although the average runoff of the two groups is 750 $\mathrm{m}^{3} / \mathrm{s}$, it can obviously restrain the intrusion distance by increasing the runoff concentration in the middle tide period after the neap tide. The difference between the two groups is mainly manifested in the days when the saltwater intrudes farthest, the biggest difference of the intrusion distance is $7.2 \mathrm{~km}$, and the difference of the intrusion distance between the two groups in other periods is not significant. The experiment also tried to increase runoff at other times, and the effect is far less than the above effect. 


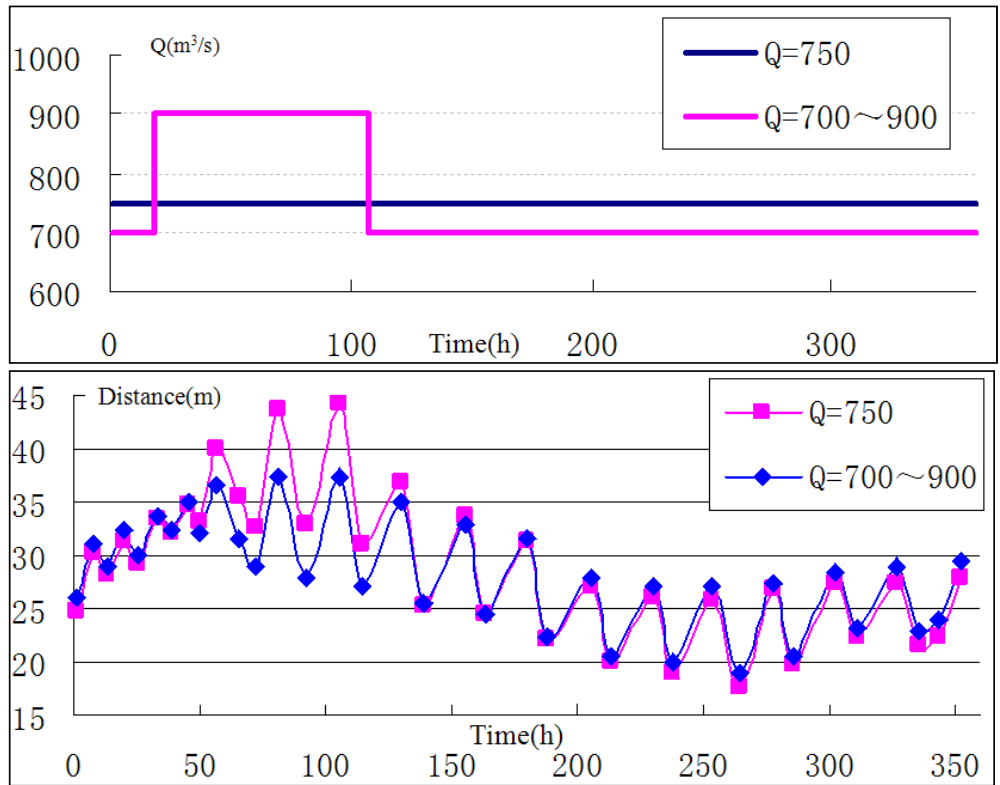

Fig.7 Distance change by runoff with the same amount and different distribution during semilunar tide

\section{Conclusion}

1) In the weak tidal estuary, tidal dynamics is the power to restrain saltwater intrusion. If the tidal range is smaller, the distance of salt water intrusion is farther. The farther the salty boundary is from the estuary, the more sensitive the influence of runoff on the salty boundary is.

2) Under the condition of semi-monthly tide, the effect of different runoff on the salty boundary is the most prominent in the middle tide period after the neap tide, then the difference is gradually reduced, and the difference is the smallest during the neap tide period.

3 ) increasing the runoff in the middle tide period after neap tide can effectively inhibit the intrusion of saltwater.

\section{Reference}

1. Pritehard D W. Estuarine hydrograPhy[J]. Advan Geophys, 1952, 1,243-280.

2. Gong W, Shen J, 2011. The response of salt intrusion to Changes in river discharge and tidal mixing during the dry season in the Modaomen Estuary, China. Continental Shelf Research, 31(7/8): 769-788.

3. Luo dan. Practice of saltwater intrusion test in the Modaomen Estuary [J]. Techenical Supervision in Water Resources, 2011, 19(5).

4. Gao shiyou, Chenzishen. Analysis on Salinity Transport Mechanism of Dry Season in Modaomen waterway of Pearl River [J]. Marine Science Bulletin, 2016(6):625-631.

5. Lu chen etc.. Investigation of the timing of water diversion to restrain saline water intrusion in Modaomen estuary [J]. Journal of Hydrodynamics, 2014, 29(2): 197-204.
6. Chen rongli etc.. Analysis of the mechanism on the saltwater intrusion in Modaomen estuary [J]. Journal of Hydrodynamics, 2011, 26(3):312-317.

7. Lu chen etc.. Experimental study on between tide and saltwater intrusion distance $[\mathrm{J}]$. Advances in Water Science, 2013, 21(2): 251-257. 